\title{
Non-human immunodeficiency virus-related Kaposi's sarcoma of the oropharynx: a case report and review of the literature
}

Erika Crosetti $^{* *}$ and Giovanni Succo ${ }^{2}$

\begin{abstract}
Introduction: Kaposi's sarcoma is a malignant, slowly progressing, mesenchymal neoplasm characterized by a proliferation of connective tissue and capillaries. Clinical presentation is usually as nodules and red-purple plaques. This case report not only represents an uncommon presentation of Kaposi's sarcoma in a non-immunocompromised patient, but also supports the role of viral infection in the pathogenesis of this disease. It provides some interesting information about this rare disease, particularly in patients who are human immunodeficiency virus negative.

Case presentation: A 48-year-old Caucasian man presented with a sensation of a foreign body in his throat, accompanied by stomatolalia. Maxillofacial and neck magnetic resonance imaging confirmed the presence of a voluminous solid mass at the base of his tongue with oropharyngeal space reduction. Histological analysis indicated that the lesion was compatible with ulcerated Kaposi's sarcoma of the oropharynx. Results of serological tests for human immunodeficiency virus infection were negative as was the result of the human herpesvirus-8 test, but the cytomegalovirus test result was positive.

Conclusions: This case is unusual because the patient had only oropharyngeal localization of disease, without evidence of immunosuppression or the typical background or risk factors suggesting the classic or endemic form of Kaposi's sarcoma. Isolated cases of Kaposi's sarcoma with oropharyngeal manifestations not associated with human immunodeficiency virus infection are rare, and only 15 cases have been reported to date. At present, its localization, microscopic and histological characteristics, and patterns of progression are the main tools used for differential diagnosis of Kaposi's sarcoma from other vascular neoplasms.
\end{abstract}

Keywords: HIV infection, Kaposi's sarcoma, Oropharynx

\section{Introduction}

Kaposi's sarcoma, the most common neoplasm associated with acquired immunodeficiency syndrome (AIDS), is a malignant, slowly progressing, mesenchymal neoplasm characterized by proliferation of connective tissue and capillaries. Clinical presentation is usually as nodules and red-purple plaques [1]. Here we present a case of Kaposi's sarcoma of the oropharynx that was unrelated to human immunodeficiency virus (HIV) infection. Isolated cases of Kaposi's sarcoma with oropharyngeal manifestations not associated with HIV infection are rare, and only 15 cases have been reported to date $[2,3]$.

\footnotetext{
* Correspondence: erikacro73@yahoo.com

'ENT Department, Martini Hospital, Turin, Italy

Full list of author information is available at the end of the article
}

\section{Case presentation}

A 48-year-old Caucasian man presented to our department referring the sensation of a foreign body in his throat, accompanied by stomatolalia. His family came from Sardinia. The man, a clerk, did not smoke and drank only socially. He was otherwise in good general health. An endoscopic examination showed the presence of a voluminous red-purple lesion at the base of his tongue, mobile, and reducing his oropharyngeal airway. Maxillofacial and neck magnetic resonance imaging confirmed the presence of a voluminous solid mass at the base of his tongue with oropharyngeal space reduction (Figures 1 and 2). He was subjected to direct microlaryngoscopy and carbon dioxide $\left(\mathrm{CO}_{2}\right)$ laser excision of the mass. The surgical margins were negative. Histological analysis indicated that the lesion was compatible with ulcerated Kaposi's sarcoma of

\section{Biomed Central}

(c) 2013 Crosetti and Succo; licensee BioMed Central Ltd. This is an open access article distributed under the terms of the Creative Commons Attribution License (http://creativecommons.org/licenses/by/2.0), which permits unrestricted use, distribution, and reproduction in any medium, provided the original work is properly cited. 


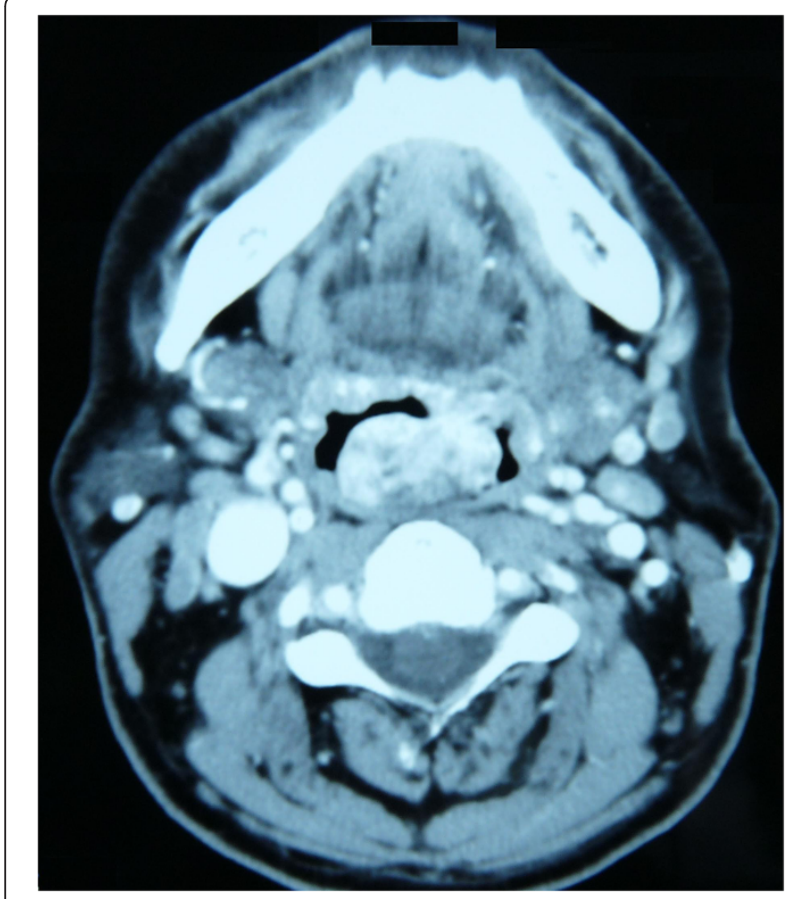

Figure 1 Maxillofacial and neck magnetic resonance imaging (axial view): presence of a voluminous solid mass at the base of the tongue with oropharyngeal space reduction.

the oropharynx. The postoperative period was uneventful. The patient was married, had regular sexual activity with his wife and reported that he did not practice oral sex. He also denied any intravenous drug abuse and he had never received immunosuppressive therapy. The results

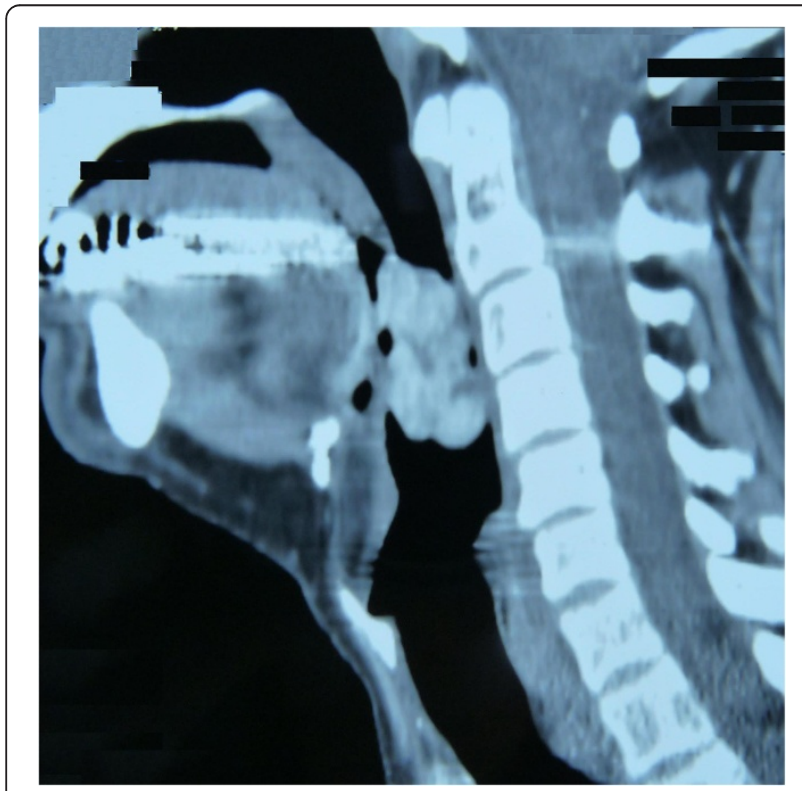

Figure 2 Maxillofacial and neck magnetic resonance imaging (sagittal view): voluminous mass at the base of the tongue. of serological tests for HIV were negative, and the patient also underwent dermatological examination. Clinical and radiological examination did not reveal any other localizations of disease. The human herpesvirus-8 (HHV8) test result was negative, but the cytomegalovirus test result was positive. He has undergone regular follow-up and is disease-free at the present time.

\section{Discussion}

Kaposi's sarcoma was described for the first time in 1872 by Moritz Kaposi using the term "multiple idiopathic hemorrhagic sarcoma" [1]. This disease is characterized by a variety of clinical and histological patterns. It is a malignant neoplasm that follows an indolent and usually protracted course. Kaposi's sarcoma is generally classified into four forms [2-5]: classic or endemic; African; epidemic; or associated with renal transplantation.

The classic or endemic form usually affects males (male to female ratio is 15:1) who live in Mediterranean countries with a peak incidence between 50 and 70 years of age. Clinically, macular lesions are observed at the level of the trunk and inferior limbs, with a tendency to manifest as nodules and plaques. This form generally has a long clinical course (10 to 15 years) with slow progression, and patients often die of other causes. Its localization in the oral cavity and oropharynx is rare and occurs late in the course of disease [2,3]. In a review in 1975, Farman and Uys [6] identified 50 patients with an endoral localization of Kaposi's sarcoma. These patients had the classic form of the disease, although diagnostic criteria were cutaneous localizations on the lower limbs.

The African form is typical in the central regions of Africa, and most frequently affects males between 25 and 40 years of age. Clinically, two subtypes have been identified [5]: a less aggressive type, characterized by the presence of plaques and cutaneous nodules with slow progression similar to the classic form and a more aggressive variety, which typically manifests in pediatric patients, in which there is visceral and lymph node involvement, in addition to classic cutaneous and mucosal lesions. This form has an extremely poor prognosis and patients usually die of gastrointestinal hemorrhage within 2 to 3 years after diagnosis. Oral and oropharyngeal localizations of the disease are rare in both subtypes of the African form [5].

The epidemic form is typical in patients with AIDS, and represents about $90 \%$ of malignant neoplasms diagnosed in these individuals. On clinical examination, the epidemic form is characterized by the appearance of disseminated mucocutaneous lesions associated with visceral and lymph node involvement. Localizations in the oral cavity and oropharynx are frequent and often represent the first symptom of disease. The clinical course of this form is dismal, as patients die quickly either from progression 
of disease or secondary complications associated with immunodeficiency [5-7].

In 1991, Chockley and Coke [8] reported that, in patients with AIDS and Kaposi's sarcoma, the presence of localizations in the oral cavity and oropharynx were probably associated with progression of disease. In $77 \%$ of cases, localizations were observed on the palate, on the gums in $36 \%$, and on the dorsal surface of the tongue in $15 \%$. The gingival mucous and lips are less frequently involved. Such lesions, initially asymptomatic, can become ulcerous and painful.

The form of Kaposi's sarcoma associated with renal transplantation has an incidence of $0.4 \%$ in the USA. The clinical course shows slow progression, but can be rapidly fatal in some cases due to massive visceral involvement. The extent of disease is directly proportional to the degree of immunodeficiency. Localizations in the oral cavity or oropharynx are rare in this subtype $[4,9]$.

On histological examination, Kaposi's sarcoma is characterized by a rich cellular component without atypia and with vascular lacunae. The stroma, in which blood vessels are present, is rich in extravasated erythrocytes and hemosiderin deposits. The four clinical forms of the disease present with nearly identical histological characteristics [9].

This case is unusual because our patient had only oropharyngeal localization of disease, without evidence of immunosuppression or the typical background or risk factors suggesting the classic or endemic form of Kaposi's sarcoma. In other cases described in the literature, the lesions generally were localized on the posterior wall of the pharynx and were small. In our case, the imaging showed the presence of a voluminous solid mass at the base of the tongue with oropharyngeal space reduction $[2,3]$.

The etiology of Kaposi's sarcoma is still widely debated, although a viral origin is the most commonly accepted hypothesis at present. According to some authors $[10,11]$, Kaposi's sarcoma is not a true neoplasm, but rather a hyperplastic reaction caused by angiogenetic factors released from either CD4+ lymphocytes or viruses. Recent studies have shown that there is a close correlation between Kaposi's sarcoma and HHV8. In particular, the presence of genomic HHV8 deoxyribonucleic acid (DNA) is a diagnostic tool for differentiating this neoplasm from other vascular tumors, such as hemangioendothelioma, kaposiform hemangioendothelioma, angiosarcoma, fibrosarcoma, and arteriovenous malformations $[12,13]$.

In 1998, Hisaoka et al. [14] evaluated 93 cases of benign and malignant vascular lesions. All patients had a diagnosis of Kaposi's sarcoma and all were positive for HHV8. More recently, the identification of HHV8 as a possible etiologic factor has suggested the potential efficacy of antiviral agents such as protease inhibitors in the treatment of Kaposi's sarcoma. In 1998, Benfield et al. [15] described three cases of Kaposi's sarcoma in complete remission after administration of protease inhibitors.

In our patient, the result of the HHV8 test was negative, but the result of the cytomegalovirus test was positive. In the literature, there is good evidence that cytomegalovirus could play a role in the pathogenesis of this disease. DNA from the virus has been localized to the tumor cells of Kaposi's sarcoma by in situ hybridization methods, in non-HIV-related Kaposi's sarcoma cases as well as those associated with HIV infection [16-20]. The role of cytomegalovirus in tumorigenesis is accomplished by the integration of a portion of its DNA into the host genome and, possibly, by amplification or mutation of oncogenetic sequences, in keeping with traditional models of virally induced tumor production [21].

Furthermore, the patient's family came from Sardinia, even though he had grown up in the Piedmont region of Italy. The frequency of classic (non-HIV-related) Kaposi's sarcoma is high in Sardinia [22]. Cerimele et al. have found that the human leukocyte antigen (HLA)-DR5 allele is greatly overrepresented in Sardinians with Kaposi's sarcoma (significance level of $\mathrm{P}<0.001$ ). By contrast, the HLA-DR3 allele associated with autoimmune diseases such as diabetes mellitus, Sjögren's syndrome, and celiac sprue [22], is uncommon, compared with the control population. To add further support to these observations, other authors have shown that human leukocyte antigen (HLA)-DR5 is also common in patients who have HIV with this neoplasm [23]. The absence of the HLA-D3 allele in patients affected by non-HIV-related Kaposi's sarcoma may reflect the relative lack of an immune response as a factor in the pathogenesis of this tumor.

Regarding therapeutic planning, as Kaposi's sarcoma is a systemic multifactorial disease, management is based on symptoms. In general, the majority of patients with nonHIV-related Kaposi's sarcoma and oral and/or oropharynx localization do not require specific treatment if symptoms such as odynophagia, dysphagia, and hemorrhage at other sites are not present. There are several treatment options for patients with the classic form and oral and/or oropharynx localization: $\mathrm{CO}_{2}$ or argon laser to minimize the possibility of bleeding; radiotherapy, Kaposi's sarcoma is relatively radiosensitive, requiring a dose less than $2000 \mathrm{rad}$; intralesional or systemic chemotherapy with vinblastine (alone or in combination with other chemotherapeutic drugs); topical treatments are generally well tolerated, inexpensive, and repeatable, thus avoiding systemic immunosuppression.

This case report not only represents an uncommon presentation of Kaposi's sarcoma in a non-immunocompromised patient, but also supports the role of viral infection in the pathogenesis of this disease. Non-HIVrelated Kaposi's sarcoma is probably caused by a similar mechanism to AIDS-related Kaposi's sarcoma, which 
is related in part to constitutive susceptibility to viral oncogenesis (perhaps linked to the human leukocyte antigen (HLA)-DR5 locus). Cytomegalovirus probably plays a role in the development of the disease, in concert, in most cases, with concomitant immunodeficiency.

\section{Conclusions}

Cases of Kaposi's sarcoma with non-HIV-related oropharyngeal manifestations are rare, and to date only 15 cases have been reported in the literature. At present, its localization, microscopic and histological characteristics, and patterns of progression are the main tools used for differential diagnosis of Kaposi's sarcoma from other vascular neoplasms.

\section{Consent}

Written informed consent was obtained from the patient for publication of this manuscript and accompanying images. A copy of the written consent is available for review by the Editor-in-Chief of this journal.

\section{Competing interests}

Both authors declare that they have no competing interests.

\section{Authors' contributions}

EC visited the patient, diagnosed the disease and analyzed and interpreted the patient data with regard to the oncological disease. GS performed the operation and regularly visited the patient. Both authors read and approved the final manuscript.

\section{Author details}

${ }^{1}$ ENT Department, Martini Hospital, Turin, Italy. ${ }^{2}$ ENT Department, S. Luigi Gonzaga Hospital, University of Turin, Turin, Italy.

Received: 16 April 2013 Accepted: 29 October 2013

Published: 31 December 2013

\section{References}

1. Jindal JR, Campbell BH, Ward TO, Almagno US: Kaposi's sarcoma of the oral cavity in a non-AIDS patient: case report and review of the literature. Head Neck 1995, 17(1):64-68.

2. Fusetti M, Chiti-Batelli S, Eibstein A, Hueck S, Nardi F: Isolated oropharyngeal Kaposi's sarcoma in non-AIDS patient: differences and similarities with spindle-cell haemangioendothelioma. J Lanyngol Otol 2001, 115(4):330-332.

3. Ficarra G, Berson AM, Silverman S, Quivey JM, Lozada-Nur F, Sooy DD, Migliorati CA: Kaposi's sarcoma of the oral cavity: a study of 134 patients with a review of the pathogenesis, epidemiology, clinical aspects and treatment. Oral Surg Oral Med Oral Pathol 1988, 66(5):543-550.

4. Quinibi WY, Barri Y, Alfurayh O, Almeshari K, Khan B, Taher S, Sheth K: Kaposi's sarcoma in renal transplant recipients: a report on 26 cases from a single institution. Transplant Proc 1993, 25(1Pt2):1402-1405.

5. Krigal RL, Friedman-Kien AE: Kaposi's sarcoma in AIDS: diagnosis and treatment. In AIDS: Etiology, Diagnosis, Treatment and Prevention. 1st edition. Edited by DeVita VT, Hellman S, Rosenberg SA. Philadelphia, PA: JB Lippincott; 1988:245-261

6. Farman AG, Uys PB: Oral Kaposi's sarcoma. Oral Surg 1975, 39(2):288-296.

7. Beckstead JH: Oral presentation of Kaposi's sarcoma in a patient without severe immunodeficiency. Arch Pathol Lab Med 1992, 116(5):543-545.

8. Chockley B, Coke JM: Treatment modalities for intraoral Kaposi's sarcoma. Spec Care Dentist 1991, 11(6):231-233.

9. Wick MR: Kaposi's sarcoma unrelated to the acquired immunodeficiency syndrome. Curr Opin Oncol 1991, 3(2):377-383.

10. Schwartz R: Kaposi's sarcoma: advances and perspectives. J Am Acad Dermatol 1996, 34(5 Pt 1):804-814.
11. Whitby D, Howard M, Tenant-Flowers M, Brink N, Copas A, Boshoff C, Hatzioannou T, Suggett FE, Aldam DM, Denton AS: Detection of Kaposi sarcoma associated herpesvirus in peripheral blood of HIV-infected individuals and progression to Kaposi's sarcoma. Lancet 1995, 346(8978):799-803.

12. Moore PS, Chang Y: Detection of herpesvirus-like DNA sequences in Kaposi's sarcoma in patients with and those without HIV infection. New Engl J Med 1995, 332(18):1181-1185.

13. Cattani P, Capuano M, Cerimele F, La Parola IL, Santangelo R, Masini C, Cerimele D, Fadda G: Human herpesvirus 8 seroprevalence and evaluation of nonsexual transmission routes by detection of DNA in clinical specimens from human immunodeficiency virus-seronegative patients from central and southern Italy, with and without Kaposi's sarcoma. J Clin Microbiol 1999, 37(4):1150-1153.

14. Hisaoka M, Hashimoto H, Iwamasa T: Diagnostic implication of Kaposi's sarcoma-associated herpesvirus with special reference to the distinction between spindle cell haemangioendothelioma and Kaposi's sarcoma. Arch Pathol Lab Med 1998, 122(1):72-76.

15. Benfield T, Kirk O, Elbrønd B, Pedersen C: Complete histological regression of Kaposi's sarcoma following treatment with protease inhibitors despite persistence of HHV-8 in lesions. Scand J Infect Dis 1998, 30(6):613-615.

16. Haguenau F, Michelson-Fiske S: Cytomegalovirus: nucleocapsid assembly and core structure. Intervirology 1975, 5(5):293-299.

17. Boldogh I, Beth E, Huang ES, Kyalwazi SK, Giraldo G: Kaposi's sarcoma. IV. Detection of CMV DNA, CMV RNA and CMNA in tumor biopsies. Int J Cancer 1981, 28(4):469-474.

18. Nelson JA, Fleckenstein B, Galloway DA, McDougall JK: Transformation of $\mathrm{NIH} 3 \mathrm{~T} 3$ cells with cloned fragments of human cytomegalovirus strain AD169. J Virol 1982, 43(1):83-91.

19. Clanton DJ, Jariwalla RJ, Kress C, Rosenthal LJ: Neoplastic transformation by a cloned human cytomegalovirus DNA fragment uniquely homologous to one of the transforming regions of herpes simplex virus type 2. Proc Natl Acad Sci U S A 1983, 80(12):3826-3830.

20. Fenoglio CM, Oster MW, Lo Gerfo P, Reynolds T, Edelson R, Patterson JA, Madeiros E, McDougall JK: Kaposi's sarcoma following chemotherapy for testicular cancer in a homosexual man: demonstration of cytomegalovirus RNA in sarcoma cells. Hum Pathol 1982, 13(10):955-959.

21. Charpentier B: Cytomegalovirus and immunomodulation. Nephrologie 1988, 9(4):163-165

22. Cerimele D, Contu L, Scappaticci S, Cottoni F: Kaposi's sarcoma in Sardinia: an epidemiologic and genetic investigation. Ann N Y Acad Sci 1984, 437:216-227.

23. Pollack MS, Safai B, Myskowski PL, Gold JW, Pandey J, Dupont B: Frequencies of HLA and Gm immunogenetic markers in Kaposi's sarcoma. Tissue Antigens 1983, 21(1):1-8.

\section{doi:10.1186/1752-1947-7-293}

Cite this article as: Crosetti and Succo: Non-human immunodeficiency virus-related Kaposi's sarcoma of the oropharynx: a case report and review of the literature. Journal of Medical Case Reports 2013 7:293.

\section{Submit your next manuscript to BioMed Central and take full advantage of:}

- Convenient online submission

- Thorough peer review

- No space constraints or color figure charges

- Immediate publication on acceptance

- Inclusion in PubMed, CAS, Scopus and Google Scholar

- Research which is freely available for redistribution 